
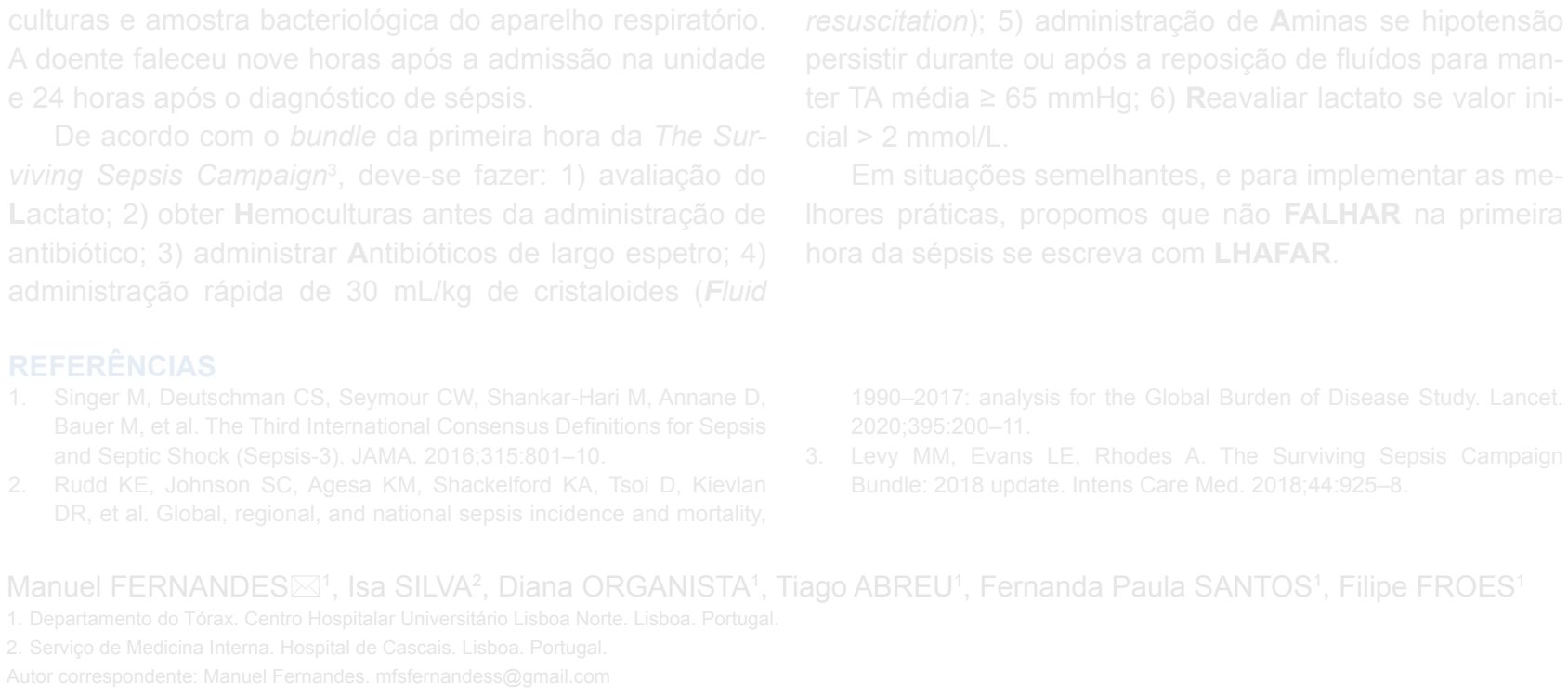

\section{O Impacto da Pandemia COVID-19 na Saúde Mental}

\section{The Impact of the COVID-19 Pandemic on Mental Health}

Palavras-chave: Coronavírus; Pandemia; Saúde Mental Keywords: Coronavirus; Mental Health; Pandemics

A quarentena profilática associada à pandemia COVID-19 origina uma série de riscos para a saúde mental. Os estudos publicados sobre este tema baseiam-se em quarentenas de grupos pequenos, devido principalmente aos vírus SARS-CoV1, MERS-CoV, HINI e ao Ébola. ${ }^{1}$ Os dados foram obtidos em estudos com amostras englobando apenas algumas centenas de pessoas, e por períodos relativamente curtos, de 10 a 21 dias de isolamento. Nunca se verificou uma quarentena massiva de milhões de pessoas em simultâneo, e sem um término à vista, o que corresponde a um aspeto negativo para a resiliência da saúde mental.

Se é verdade que o isolamento é importante para proteger a nossa saúde física, impedindo o contágio pelo vírus, também é verdade que quanto mais tempo estivermos isolados maiores serão os riscos de sofrermos doenças psiquiátricas. ${ }^{2}$ Sabemos que a quarentena pode originar uma constelação de sintomas psicopatológicos, designadamente, humor deprimido, irritabilidade, ansiedade, medo, raiva, insónia, etc.. ${ }^{1}$ Além disso, identificaram-se consequências a longo prazo para a saúde mental. Cerca de três anos após a quarentena, verificou-se um aumento de risco para o aparecimento de abuso de álcool, sintomas de perturbação de stress pós-traumático e depressão. ${ }^{3}$

Neste contexto de isolamento, provavelmente irão aumentar a perturbações depressivas e as perturbações de stress pós-traumático. ${ }^{4}$ Para além do stress associado ao receio de contrair a doença, existem ainda outros fatores que aumentam a vulnerabilidade psicológica das pessoas em quarentena. Refiro-me às dificuldades económicas decorrentes desta pandemia, nomeadamente ao risco do aumento do desemprego que está associado a um agravamento da saúde mental da população. ${ }^{5}$

Uma última referência sobre a forma como está a ser feito o luto das pessoas que morrem durante este período de pandemia. Devido às medidas preventivas de saúde pública, as cerimónias fúnebres estão a ser realizadas quase sem pessoas. Muitos familiares e amigos estão privados de se despedirem de quem morre; ou seja, não existem abraços, nem o habitual consolo do luto feito em comunidade. Isto acarreta um enorme sofrimento para todos aqueles que perdem os seus familiares e amigos. Em suma, vivemos tempos estranhos. Neste período levantam-se muitas dúvidas, e irá certamente demorar muitos anos até compreendermos qual foi o verdadeiro impacto da pandemia na saúde mental.

\section{REFERÊNCIAS}

1. Brooks SK, Webster RK, Smith LE, Woodland L, Wessely S, Greenberg $\mathrm{N}$, et al. The psychological impact of quarantine and how to reduce it: rapid review of the evidence. Lancet. 2020;395:912-20.
2. Reynolds DL, Garay JR, Deamond SL, Moran MK, Gold W, Styra R. Understanding, compliance and psychological impact of the SARS quarantine experience. Epidemiol Infect. 2008;136:997-1007.

3. Wu P, Liu X, Fang Y, Fan B, Fuller CJ, Guan Z, et al. Alcohol abuse/ 
dependence symptoms among hospital employees exposed to a SARS outbreak. Alcohol Alcohol. 2008;43:706-12.

4. Hawryluck L, Gold WL, Robinson S, Pogorski S, Galea S, Styra R. SARS control and psychological effects of quarantine, Toronto, Canada.
Emerg Infect Dis. 2004:10:1206-12.

5. Strandh M, Winefield A, Nilsson K, Hammarström A. Unemployment and mental health scarring during the life course. Eur J Public Health. $2014 ; 24: 440-5$

\section{Pedro AFONSO $\square^{1}$}

1. Clínica Universitária de Psiquiatria e Psicologia Médica. Faculdade de Medicina. Universidade de Lisboa. Lisboa. Portugal. Autor correspondente: Pedro Afonso. pedromafonso@netcabo.pt

Recebido: 07 de abril de 2020 - Aceite: 08 de abril de 2020 | Copyright @ Ordem dos Médicos 2020 https://doi.org/10.20344/amp.13877

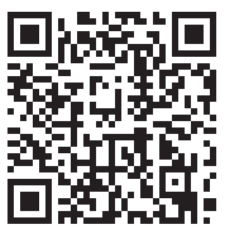

